\title{
RELAÇÕES SOCIEDADE-NATUREZA EM PERSPECTIVA: EDUCAÇÃO AMBIENTAL NAS LICENCIATURAS EM QUÍMICA DOS INSTITUTOS FEDERAIS NO BRASIL
}

\author{
Wesley F. Magela ${ }^{a}$ e Nyuara A. S. Mesquita ${ }^{b, *,(1)}$ \\ a Secretaria de Estado de Educação de Goiás, 76350-000 Rubiataba - GO, Brasil \\ 'Instituto de Química, Universidade Federal de Goiás, Câmpus Samambaia, 74690-900 Goiânia - GO, Brasil
}

Recebido em 27/05/2020; aceito em 16/11/2020; publicado na web em 15/12/2020

\begin{abstract}
SOCIETY-NATURE RELATIONSHIPS IN PERSPECTIVE: ENVIRONMENTAL EDUCATION IN TEACHER TRAINING COURSES IN CHEMISTRY OF FEDERAL INSTITUTES IN BRAZIL. Environmental Education arises in the context of understanding the urgency of the environmental crisis and the need to seek answers for its mitigation. The different perspectives of $\mathrm{AE}$ compete for the affirmation of notions of the world, of society, of social well-being, of work and of life. The research investigated the conceptions of Environmental Education (EA) present in the scope of the Federal Institutes, having as corpus the Pedagogical Course Project (PPC) of teacher training courses in chemistry offered in these institutions in 23 states and in the Federal District. The documents were analyzed, in their entire body, with the aid of Textual Discursive Analysis (ATD). The results demonstrate the predominance of a conservative environmental education, of an apolitical and biologizing character, in the analyzed documents, what can be reflected in the profile of the chemical educator to be formed in these institutions.
\end{abstract}

Keywords: teacher training courses in chemistry; Federal institutes; enviromental education; society-nature relationships.

\section{O SURGIMENTO DO CAMPO DA EDUCAÇÃO AMBIENTAL: CONJUNTURA INTERNACIONAL E O CONTEXTO BRASILEIRO}

O presente artigo traz reflexões teóricas e empíricas relacionadas ao contexto ambiental na formação de professores de Química no âmbito dos Institutos Federais (IF). Para o desenvolvimento das argumentações aqui tecidas, é importante refletirmos, incialmente, sobre a problemática ambiental tendo em vista suas vertentes teóricas e o cenário de estruturação desse campo de conhecimento.

No sentido de esclarecer as diferenças entre alguns dos termos usados nesse texto, nos apropriamos da compreensão de Ribeiro e Cavassan, ao diferenciarem Natureza, Ambiente e Meio Ambiente. De acordo com os autores, a Natureza é a realidade dada, a qual existe independentemente da reação com o ser humano. O Ambiente refere-se à realidade apreendida, no que diz respeito à compreensão do ser humano sobre os fenômenos que o circundam. Já o Meio Ambiente traz imbricadas as relações de apropriação do homem sobre a natureza. ${ }^{1}$

O Meio Ambiente, compreendido, desde os primórdios da humanidade, como habitat e origem infindável de recursos, sempre refletiu as consequências do desenvolvimento de um modelo social insustentável. Alvo de agravos, da exploração e do descomedimento humano, o mundo natural não era questionado em sua capacidade de sustento da raça humana. Essa consciência só surge quando, ao final da primeira metade do século XX, o potencial destrutivo da ação antrópica sobre o meio ambiente se torna tão evidente que leva a humanidade a se questionar sobre sua própria sobrevivência. ${ }^{2}$

A prosperidade econômica e social nos anos que se seguiram ao pós-guerra, tidos como os anos dourados do capitalismo, fundamentada em um sistema de produção e um padrão consumista que compreendiam o ambiente natural como estoque infinito de matéria-prima, trouxe consigo a preocupação com a capacidade de manutenção do conforto e com a perspectiva de uma possível escassez dos recursos naturais. ${ }^{3}$

\footnotetext{
*e-mail: nyuara@ufg.br
}

O modelo societário que compreende o desenvolvimento econômico como resposta para todos os problemas sociais, ao não enxergar seus efeitos no meio ambiente e ao não propor limites no uso desse e dos recursos dele advindos, foi responsável por incidentes de grande monta, que trazidos à tona pelas mídias de massa, despertaram nos indivíduos a preocupação com a segurança social. Desastres como a poluição do ar, em Londres, em 1952; a contaminação por mercúrio da baía de Minamata, no Japão, em 1954; os acidentes radioativos nas usinas de Three Miles Island, nos EUA, em 1979, são apontados como exemplos de catástrofes, com perda de vidas humanas, que lançaram os olhos da humanidade sobre a gravidade e a urgência da questão ambiental. , $^{2,}$

Cabe ressaltar, ainda, o papel ambíguo da ciência no processo de construção do campo ambiental. Se, por um lado, é inegável que o sistema econômico baseado no consumo em larga escala foi, e é, impulsionado pelos avanços tecnológicos possibilitados pela Ciência, caracterizados como empreendimento tecnocientífico predatório, é igualmente certo que o desvelamento e o combate aos impactos gerados por esse sistema também são ensejados por ela. ${ }^{5}$

A publicação do livro Primavera Silenciosa, da americana Rachel Carson, no qual a autora denunciava os problemas decorrentes do uso do DDT, mostrou-se um importante marco para o questionamento sobre o papel do desenvolvimento científico na produção do desequilíbrio ambiental, evidenciando a necessidade de se olhar e discutir as questões ambientais no sentido da sobrevivência das gerações futuras. ${ }^{6}$

A necessidade de se discutir as questões relacionadas ao meio ambiente impulsiona a emergência da pauta ambiental em várias frentes. O termo 'Educação Ambiental' (EA) é utilizado pela primeira vez durante a Conferência de Educação da Universidade de Keele, realizada na Inglaterra no ano de 1965. Sua utilização se deu na discussão das possíveis contribuições da educação na transformação de comportamentos oriundos de uma herança cultural de degradação ambiental em práticas e valores orientados para uma cultura de zelo com o meio ambiente, principalmente através da inserção de conceitos de ecologia e de uma perspectiva preservacionista. $^{7}$ 
De forma análoga ao surgimento do termo, a trajetória da institucionalização da EA é marcada por grandes eventos regionais e mundiais apresentados no Quadro 1.

No contexto brasileiro, é notável que os eventos internacionais citados, que despertavam para a necessidade da expansão do conhecimento, a organização e a disseminação das políticas ambientais no âmbito da Educação, estimularam o campo da EA no país, em sua formação e trajetória. As recomendações externas, oriundas dos fóruns citados e mesmo dos organismos internacionais, levaram, inicialmente, à criação da SEMA (Secretaria Especial de Meio Ambiente), ligada ao Ministério do Interior, no ano de 1973. Sendo o primeiro órgão de gestão ambiental formado na esfera do governo federal para tratar das questões ambientais, a concepção da SEMA, assim como de outras entidades espalhadas pelo país, se deu mais por força maior de grupos, governos e organismos internacionais que por espontaneidade e iniciativa próprios do cenário interno. ${ }^{7}$

Um fato interessante a se notar na perspectiva da constituição da EA no Brasil, é que, embora desde 1981 com a instituição da Política Nacional de Meio Ambiente pela Lei 6.398/81, já houvesse a previsão de EA para todos os níveis de ensino, ${ }^{11}$ essa se dá inicialmente muito mais por iniciativa do setor ambiental que pelo campo da Educação. Na esfera do governo federal, por exemplo, enquanto a SEMA possuía uma divisão de EA, objetivando o esclarecimento da população brasileira quanto ao uso comedido dos recursos naturais, desde sua origem, o Ministério da Educação (MEC) só viria a constituir um grupo de trabalho sobre EA, que ficaria conhecido como COEA (Comissão Especial de Educação Ambiental), em 1991, com a perspectiva da Rio-92 no ano seguinte.

A década de 1990, e a seguinte, presenciam diversas ações, por parte do governo federal, no sentido do enraizamento da EA no cenário brasileiro. ${ }^{7}$ Uma dessas ações surge como um dos reflexos da Rio- 92, quando o poder executivo federal institui, em 1994, o Programa Nacional de Educação Ambiental (PRONEA), sob responsabilidade do MEC e do MMA (Ministério do Meio Ambiente), na figura do IBAMA (Instituto Brasileiro do Meio Ambiente e dos Recursos Naturais Renováveis), contando com o auxílio do Ministério da Ciência e Tecnologia (MCT) e do Ministério da Cultura (MinC).

Outro exemplo é a definição, pela COEA em 1997, dos Parâmetros Curriculares Nacionais (PCN). Com o objetivo de implementar uma política continuada de formação de professores com uma compreensão de EA de caráter transversal, os PCN tiveram que superar o dilema de inserir a EA, que é necessariamente um tema interdisciplinar, em um sistema educacional pautado pela compreensão disciplinar do processo formativo e pela rigidez do currículo. Concebida em 1997, a primeira versão dos PCN era dirigida apenas aos professores da primeira fase do Ensino Fundamental ( $1^{\circ}$ ao $4^{\circ}$ ano). Em 1998 a abrangência de sua ação é ampliada para a segunda fase ( $5^{\circ}$ ao $8^{\circ}$ ano) e passa a contemplar todo o Ensino Fundamental. O fim da década marca a oficialização da presença da EA nos diferentes níveis e modalidades de ensino, através da Política Nacional de Educação Ambiental (PNEA), instituída pela Lei 9.795, sancionada em 1999. ${ }^{12}$

Um importante apontamento, entretanto, é feito por Layrargues quando sinaliza que, embora a garantia da inserção da EA na Educação represente uma conquista após mais de duas décadas de esforços dos educadores ambientais, essa deve ser alvo de uma análise crítica sobre os princípios, as possibilidades e as limitações da perspectiva de EA proposta no texto legal. ${ }^{13}$

Nesse sentido, apesar de apontar em seu quarto artigo, como princípios básicos da EA, um enfoque humanista e holístico, a leitura que se pode fazer da PNEA, já em seu primeiro artigo, é a de uma concepção de EA de caráter completamente antropocêntrico e conservacionista. ${ }^{14}$

Aprovado em janeiro de 2001 através da lei 10.172, o Plano Nacional de Educação (PNE) para o decênio 2001-2011, em consonância com a PNEA, consolidou a abordagem integrada e transversal da EA como uma das metas e objetivos para o Ensino Fundamental. Sua versão seguinte, entretanto, a despeito de trazer como uma de suas diretrizes a "promoção dos princípios do respeito aos direitos humanos, à diversidade e à sustentabilidade socioambiental", ${ }^{15}$ não menciona a EA de forma direta, nem contêm objetivos para seu estímulo.

Resultado da necessidade de orientações quanto implementação da PNEA e de definição de suas características gerais, as Diretrizes Nacionais Curriculares para a Educação Ambiental (DCNEA) são estabelecidas em junho de 2012 pela Resolução $N^{\circ} 2$ do Conselho Nacional de Educação, reafirmando a EA como "prática educativa integrada e interdisciplinar". ${ }^{16}$

Cassiano aponta o caráter crítico-transformador do papel da EA destacado nas DCNEA ao associarem os agravos ao meio ambiente

Quadro 1. Quadro resumo com eventos mundiais e suas principais contribuições na trajetória de institucionalização da EA

\begin{tabular}{|c|c|c|}
\hline Evento/Local & Ano de realização & Principais contribuições na sistematização da área de Educação Ambiental \\
\hline Conferência de Estocolmo (Estocolmo) & 1972 & $\begin{array}{l}\text { - São lançadas na comunidade internacional as primeiras propostas de qualificação } \\
\text { de educadores para trabalhar com a temática ambiental e desenvolvimento de } \\
\text { métodos para a implantação da incipiente Educação ambiental. }{ }^{2} \\
\text { - Recomendação da constituição de um programa internacional de educação } \\
\text { ambiental. }\end{array}$ \\
\hline $\begin{array}{l}\text { Encontro Internacional de Educação Ambiental } \\
\text { (Belgrado) }\end{array}$ & 1975 & $\begin{array}{l}\text {-Publicação do que ficou conhecido como a Carta de Belgrado, um documento } \\
\text { que estabeleceu seis objetivos para a EA ainda considerados atuais. } \\
\text { - Criação do Programa Internacional de Educação Ambiental (PIEA). }\end{array}$ \\
\hline $\begin{array}{l}1^{\text {a }} \text { Conferência Intergovernamental de Educação } \\
\text { Ambiental (Tbilisi) }\end{array}$ & 1977 & $\begin{array}{l}\text { - Principal marco regulatório da EA por ter definido, como consequência da } \\
\text { declaração ratificada em seu encerramento, os objetivos, as características e os } \\
\text { meios orientadores do então recente campo de saber. }{ }^{1,9}\end{array}$ \\
\hline Conferência de Moscou (Moscou) & 1987 & $\begin{array}{l}\text { - Criação de um quadro teórico-metodológico que recomendava a reorientação } \\
\text { dos processos educacionais no sentido da materialização da educação ambiental. } \\
\text { Daí surge também um plano para expansão da EA durante a década de } 90 .{ }^{10}\end{array}$ \\
\hline $\begin{array}{l}\text { Conferência das Nações Unidas sobre Desenvolvi- } \\
\text { mento e Meio ambiente (Rio de Janeiro) }\end{array}$ & 1992 & $\begin{array}{l}\text { - Publicação da Agenda 21, documento que firmava compromissos para o desen- } \\
\text { volvimento da sustentabilidade e para a elevação da qualidade de vida no planeta. }\end{array}$ \\
\hline $\begin{array}{l}\text { Conferência Internacional sobre Meio Ambiente e } \\
\text { Sociedade: Educação e Consciência Pública para a } \\
\text { Sustentabilidade (Tessalônica) }\end{array}$ & 1997 & $\begin{array}{l}\text { - A EA é reconhecida, ao lado da economia, da legislação e da tecnologia, como } \\
\text { um dos quatro pilares da sustentabilidade. }\end{array}$ \\
\hline
\end{tabular}


aos tipos de relações que constituem o tecido social, em sua crítica às práticas pedagógicas de uma EA de caráter ingênuo e apolítico e ao ressaltarem o pensamento crítico-reflexivo como um dos aspectos da EA. ${ }^{17}$

Entende-se que as DCNEA promoveram uma preocupação, no âmbito das Instituições de Ensino Superior (IES), em inserir as questões ambientais em projetos institucionais no sentido de atender às normativas e que tal inserção possibilitou caminhos para que os cursos superiores passassem a discutir a problemática ambiental em suas propostas pedagógicas. Essa inserção nos projetos institucionais é ressaltada por Quinelato e Lindino (2015, p. 12) ao salientarem a necessária discussão sobre a temática ambiental nas diversas instâncias acadêmicas para a

operacionalização desses princípios dentro do espaço universitário e nos processos de gestão institucional, bem como, na reestruturação dos currículos dos cursos, ganhando visibilidade temas como as preocupações com questões socioambientais, numa perspectiva de fortalecimento dos conteúdos clássicos em consonância com o trabalho com temas complexos que a contemporaneidade nos apresenta. ${ }^{18}$

A seguir, discutiremos de forma mais específica as questões que relacionam a EA e a formação de professores, assunto que baliza o presente texto.

\section{A EDUCAÇÃO AMBIENTAL E A FORMAÇÃO DE PROFESSORES PARA A EDUCAÇÃO BÁSICA}

A formação da identidade docente é entendida como um processo de construção histórica do sujeito, cuja trajetória se dá no enlace das relações entre os indivíduos e nas representações sociais desses indivíduos. Tais representações também são estruturadas a partir de documentos, leis e normativas que regem a formação e a carreira docente. ${ }^{5}$ Dessa forma o perfil de educador presente hoje no quadro da Educação Básica é derivado das políticas que organizam e delimitam o perfil desse profissional a ser formado no âmbito dos cursos superiores.

Nessa perspectiva, as DCNEA orientam a inclusão da EA nos cursos de licenciatura ao estabelecerem que os cursos de formação inicial capacitem os futuros educadores para o desenvolvimento didático e pedagógico da dimensão ambiental, em suas atividades escolares e acadêmicas. ${ }^{16}$ Todas as resoluções referentes às diretrizes para formação de professores incluem as questões ambientais como elementos importantes para que os futuros professores possam discutir e trabalhar a EA no contexto da educação básica.${ }^{19-22}$

Destacamos que não só as licenciaturas que formam professores de áreas específicas passaram a trabalhar a EA em seus contextos formativos. Os cursos que formam professores para os anos iniciais também se apropriaram desse viés formativo. Modesto e Araújo ampliam essa discussão trazendo a ambientalização nos cursos de Pedagogia. Os autores explicitam que o curso, como lugar de abordagem da relação ação-reflexão-ação, " não pode se eximir de desvelar ao aprendente que a atual crise ambiental é decorrente da ação antropocêntrica frente ao meio ambiente que orienta a lógica de produção e que historicamente se instaurou na sociedade em que vivemos (p. 2). ${ }^{23}$

A formação de professores de Química é também orientada, de forma específica, pelas Diretrizes Curriculares Nacionais para os Cursos de Química (DCNCQ). Esse documento traz orientações para a estruturação das graduações em Química no país, nas modalidades Bacharelado e Licenciatura. A dimensão ambiental é evidenciada nesse documento ao explicitar que o profissional licenciado deve estar preparado para "compreender e avaliar criticamente os aspectos sociais, tecnológicos, ambientais, políticos e éticos relacionados às aplicações da Química na sociedade". ${ }^{22}$ É importante destacarmos que as DCNCQ não explicitam a forma de inserção da dimensão ambiental no currículo. No entanto, o fato de sinalizarem a perspectiva ambiental como componente da formação dos profissionais da química, licenciatura e bacharelado, mostra-se como elemento importante para a estruturação curricular, que veio após os anos 2000, em que muitos cursos inseriram disciplinas de Química ambiental e de EA em suas matrizes curriculares.

Contudo, considerando-se o histórico da inserção da EA na formação de professores, Sauvé aponta que embora exista um discurso de preocupação comum com o meio ambiente, materializado nas IES na propaganda de uma ambientalização curricular e no reconhecimento da EA como potencial elemento transformador da relação do indivíduo com o meio em que se encontra inserido, ainda são muitos os espaços formativos formais, que, na contramão da perspectiva crítica, expressam grande inclinação à uma formação ambiental pouco problematizadora. ${ }^{24}$

Zuin denuncia, em sua análise da ambientalização curricular de um curso de Licenciatura em Química, a visão errônea presente em grande parte desses cursos, de que as disciplinas de Química Ambiental são as que primordialmente devem dar conta da problemática ambiental. ${ }^{5}$ Cabe ressaltar que tal ponto de vista é antagônico ao preconizado pela PNEA e pelas DCNEA, que determinam a inserção da temática ambiental de forma transversal nas diferentes disciplinas. A autora alerta para a presença da concepção de que a simples aquisição de conhecimentos científicos em Química seria suficiente para dar ao licenciando capacidade de discussão e posicionamento frente a questões sociais e científicas relacionadas à problemática ambiental, ficando as disciplinas de formação humanística, dentre elas as de caráter pedagógico, responsáveis apenas por assuntos eventuais e periféricos a respeito dessa temática.

Zuin denota ainda que a perspectiva de responsabilização de apenas uma disciplina de determinado conteúdo acerca do trabalho com a questão ambiental é muito restrita. ${ }^{5}$ De acordo com a autora, o ideal seria a permeabilização de todo o currículo por essa discussão, passando, além das disciplinas teóricas e práticas, também pela pesquisa e extensão, conseguindo atingir toda a IES. Essa perspectiva seria a da ambientalização curricular, conceito desenvolvido pela Rede de Ambientalização Curricular do Ensino Superior (ACES), que compreende a inserção de conhecimentos, de critérios e de valores sociais, éticos, estéticos e ambientais nos estudos e currículos universitários, no sentido de educar para a sustentabilidade socioambiental. ${ }^{25}$

A formação de professores de química no Brasil se dá no âmbito das Instituições de Ensino Superior (IES) públicas e privadas. De acordo com dados da Plataforma e-Mec, atualmente existem 409 cursos de Licenciatura em Química ativos no país. Desses, 347 são ofertados por IES públicas e 96 são de responsabilidade dos Institutos Federais (IF).

A oferta de cursos de Licenciatura em Química no âmbito dos IF decorre da própria legislação de criação desses institutos, a partir da qual $20 \%$ da dotação orçamentária deveria ser para cursos de licenciatura e programas de formação pedagógica. ${ }^{26}$ Considerando-se que os Centros Federais de Educação Tecnológica, que precederam os IF, já ofertavam cursos de caráter tecnológico, como cursos de Química em nível médio e superior, a oferta das licenciaturas em química tornou-se um caminho natural no aproveitamento da estrutura dos institutos.

Segundo Lima, o fato desses cursos serem direcionados a determinadas áreas do conhecimento propedêutico, demonstra que há uma clara tendência para as licenciaturas dentro do contexto de 
inserção dos $\mathrm{IF}^{27} \mathrm{~A}$ autora nos chama a atenção também para o fato de que a oferta de cursos de formação de professores em instituições com vocação para a educação técnica e tecnológica se traduz em particularidades que fazem das licenciaturas nos IF um locus completamente novo, com características de formação tecnológica e diferente dos cursos oferecidos em outras IES. Ressalta-se que o termo "novo" relacionado à oferta de licenciaturas nos IF tem relação com o fato de que os cursos de licenciatura ofertados pelas universidades brasileiras remontam sua criação à década de 1930 do século passado.

Tendo em vista que os IF são responsáveis pela oferta de 1/3 dos cursos de licenciatura em Química oferecidos pelas IES públicas no país e configuram se como instituições de tradição técnica, com particularidades específicas, torna-se fundamental compreender as nuances desse locus de formação de professores e de que maneira suas propostas formativas abarcam questões importantes que envolvem perspectivas críticas, posicionamentos transformadores e questionamentos para a área de ensino de química considerando-se tanto os direcionamentos legais para a inclusão da EA no âmbito da formação de professores, quanto o contexto atual de degradação do meio do ambiente no qual faz-se necessário e urgente a discussão da problemática ambiental.

Nessa perspectiva, emerge o foco que balizou o desenvolvimento desta pesquisa que objetivou compreender a abordagem da temática ambiental, as concepções de EA e as características da formação do educador químico na perspectiva ambiental que são delineadas nas propostas pedagógicas das licenciaturas em química ofertadas pelos IF expressas nos projetos pedagógicos desses cursos. No sentido de sustentar as discussões dos dados da pesquisa, torna-se importante explicitar as diferentes correntes de pensamento relacionadas à compreensão de EA fundamentadas na literatura. No sentido de discutir as questões aqui propostas, discutiremos nos próximos tópicos as relações sociedade-natureza na EA, apresentaremos o percurso metodológico desta pesquisa e discutiremos os resultados a partir da análise realizadas nos 78 PPC dos IF.

\section{RELAÇÕES SOCIEDADE-NATUREZA NA EDUCAÇÃO AMBIENTAL: CONSERVACIONISMO, PRAGMATISMO E PERSPECTIVA CRÍTICA}

Centrando a discussão nas concepções de EA que marcaram a história de sua institucionalização no cenário nacional, faremos uso da classificação proposta por Layrargues e Lima, que distinguem tais concepções em três grandes macrotendências: conservacionista, crítica e pragmática. ${ }^{28}$ No entanto, essa não é uma classificação fechada, pois dialoga de forma coerente com outros referenciais usados para discutir as questões ambientais na formação de educadores.

A formação do campo da EA no Brasil tem como característica a presença marcante de uma ênfase conservacionista que exerceu, em um momento inicial, total predominância dentro do campo. Essa concepção, embora tenha sido alvo de críticas, e mesmo tendo passado a dividir o campo com outras compreensões de EA, ainda se faz presente nas práticas de Educação Ambiental, sobretudo entre os educadores ambientais que não fazem parte do "núcleo orientador do campo". ${ }^{28}$

O conservacionismo consiste em uma concepção de EA que embora perceba a urgência da problemática ambiental, a compreende através de uma ótica estritamente ecológica que entende o meio ambiente como simples natureza, um ente completamente afastado do homem e de qualquer construto social. Sua lógica está centrada na conservação dos recursos, seja no que tange à qualidade ou à quantidade desses. Os problemas ambientais seriam, assim, frutos da ingenuidade dos indivíduos frente à importância do mundo natural para a vida humana, resultantes do desconhecimento do homem sobre questões ecológicas, biogeoquímicas e do funcionamento dos ecossistemas. ${ }^{2,24,29,30}$

Ainda segundo essa concepção, a responsabilidade pelos impactos ambientais é atribuída a um humano genérico, distribuindo a todos os homens iguais parcelas de culpabilidade pelos danos ambientais, como se cada um fosse responsável pela produção e consumo desenfreados e pela poluição, em igual proporção. Essa ideia é rechaçada por Loureiro quando ele afirma que

É inaceitável culpar o homem como algo homogêneo, já que o que qualifica a ação predatória não é a ação humana abstratamente, mas modos específicos de relações sociais que determinam formas de uso e apropriação da natureza, pautadas na exploração intensiva do trabalho e dos recursos vitais disponibilizados pela natureza. (p. 25) ${ }^{31}$

A concepção conservacionista, desconsiderando os recortes sociais que caracterizam a sociedade de classes, ignora a distribuição desigual dos agravos e dos riscos ambientais, furtando-se à necessária denúncia dos conflitos socioambientais que permeiam a questão ambiental e das desigualdades sociais e de poder que são fruto do sistema capitalista que "sustenta um adequado padrão de vida para alguns em detrimento do péssimo padrão de vida para outros" (p. 56). ${ }^{32}$

Afastando-se de uma prática educativa despolitizada, a EA Crítica assume a luta por uma nova relação entre os seres humanos e o meio ambiente que, baseada na ideia de justiça ambiental, entende que todos os cidadãos têm direito a um ambiente limpo e saudável, se contrapondo ao padrão consumista vigente e buscando promover a distribuição dos bens ambientais de forma justa, solidária e que caminhe rumo à uma coletividade sustentável..$^{33,34}$

Defendendo a ideia de que essa nova cultura ambiental só pode ser construída em conjunto com a superação do modelo capitalista, a EA Crítica aponta que a resolução da crise ambiental não se daria, portanto, pela promoção de reformas setoriais. Se daria sim através de uma ampla renovação pluridimensional que fosse capaz de romper com o capitalismo e, consequentemente, de promover uma transformação na Ciência, nas instituições, nas relações sóciopolíticas e nos valores éticos e culturais. ${ }^{28,32,35}$

A prática pedagógica centrada nessa vertente volta-se para a formação de uma cidadania ecológica que permita ao educando se enxergar como elemento em uma estrutura socioeconômica que é carregada de uma ideologia dominante que expressa seus interesses na forma de expectativas e exigências de padrões de comportamentos. Implica também compreender que as relações de agravo observadas entre os indivíduos de uma sociedade e o meio ambiente não é fruto, como concebem as concepções conservacionistas, da ausência de conhecimento ou de empatia em relação à natureza, mas sim das condições impostas pela realidade em um dado momento histórico.

A EA crítica assume o papel da inclusão do debate, e da compreensão, das condições político-ideológicas dos mecanismos de reprodução social e de que a mediação da relação homemnatureza se dá no âmbito das relações sociais, culturais e de classes. Ainda segundo os autores, dentro dessa perspectiva "não é possível compreender os problemas ambientais dos conflitos sociais, afinal a crise ambiental não expressa problemas na natureza, mas problemas que se manifestam na natureza" (p. 68). ${ }^{32}$

Assim, contrapondo-se à reprodução das condições dadas pelo padrão social vigente, a EA Crítica aborda um fazer educacional que instrumentalize educadores e educandos, enquanto sujeitos sociais em formação, para intervir na realidade posta de forma política e questionadora e que objetive a suplantação desse modelo socioeconômico. 
Layrargues e Lima abordam uma terceira vertente em que se inscrevem as concepções de EA: a vertente pragmática. ${ }^{28}$ Os autores a enxergam como um outro momento da perspectiva conservacionista, que soube se adaptar às mudanças políticas e de mercado levadas a cabo pelo pensamento neoliberal que se impôs sobre o mundo a partir da década de 80 . Sendo fundamentada nas ideias de uma economia sustentável e no forte apelo ao ambientalismo de resultados, surgidas sobretudo durante os anos 90, essa vertente se caracteriza pela operação de mudanças superficiais e comportamentais dentro de limites estabelecidos pela lógica de mercado que, frente à nova dinâmica social, necessitava de transformações "cosméticas" na sua relação com o meio ambiente.$^{28}$

Assim como a vertente conservacionista, da qual deriva, o pragmatismo ambiental entende o meio ambiente como um ente apartado dos componentes humanos e sociais. Sua dinâmica discursiva se traduz em um mecanismo de correção das fragilidades dos sistemas produtivo e consumista por meio da mudança de comportamento dos indivíduos. O pragmatismo na EA se traduz, assim, como um mecanismo de correção de imperfeições dentro da estrutura social vigente sem, contudo, questionar a ordem socioeconômica que governa essa sociedade. Atendendo à lógica de mercado, essa tendência defende pautas como a da economia de energia e de água, da reciclagem e do consumo sustentável, viabilizando a manutenção do modelo consumista que serve ao capital. ${ }^{32}$

Sua proposta pedagógica se centra na busca por atitudes práticas, efetivas e bem-sucedidas em um curto espaço de tempo, exigidas pela urgência da crise ambiental. Assim, embora aborde conceitos como cidadania e perspectiva social, seu foco está em uma pedagogia de resultados que não aborda uma proposta de formação pela reflexão. Seu interesse é a mudança de comportamentos individuais, um agir pragmático, no qual a teoria assume importância secundária. ${ }^{36}$

Imbuída da lógica de mercado, ao qual se vincula e a cujos interesses atende, a concepção pragmática descaracteriza a natureza política da EA. Sua pedagogia passa a se caracterizar, então, por uma perspectiva domesticadora. O educando é levado a se compreender enquanto agente da transformação do modo de consumo. Cabe a ele, como cidadão em formação, a operação de mudanças em seu comportamento e na sua relação individual com o meio ambiente. É esse direcionamento que, por se associar a manutenção do modelo societário capitalista, favorece os interesses da classe dominante. Ao direcionar o indivíduo para a "conscientização ecológica", centra sua preocupação em questões como o descarte do lixo por ele produzido, com a reciclagem e com o consumo sustentável, mas o coloca em condição de alienamento em relação à lógica predatória do modo de produção capitalista. ${ }^{34}$

No âmbito da discussão da ambientalização da Química, tem ganhado cada vez mais espaço a discussão dos pressupostos da Química Verde (QV). Apoiada em doze princípios que norteiam sua ideia de sustentabilidade, essa filosofia surge no início da década de 1990, nos Estados Unidos da América, defendendo o desenho e o desenvolvimento de novas rotas sintéticas e processos químicos capazes de reduzir ou mesmo eliminar a produção de substâncias nocivas à saúde humana e ao meio ambiente. ${ }^{37,38}$

Uma importante crítica feita a essa filosofia se centra em seu caráter apolítico. Buscando caminhos para a correção das falhas geradas nos processos de desenvolvimento industrial dos processos químicos, e que levam à degradação do meio ambiente, as ideias da QV se ocupam de reformas setoriais sem, no entanto, questionar o padrão de produção e de consumo imposto, característica que, como discutimos anteriormente, se alinha aos propósitos de uma concepção pragmática da problemática ambiental. Salientamos que, embora haja críticas às perspectivas da QV no contexto da EA, alguns autores estabelecem importantes e construtivas relações entre os princípios da QV e a ambientalização dos currículos de formação de professores de química tendo em vista a inserção da dimensão ambiental nesse processo formativo. ${ }^{5,37}$

A partir de tais pressupostos, e retomando os objetivos da pesquisa, trabalhamos na investigação dos 78 PPC de licenciatura em Química dos IF no sentido de compreendermos as concepções de EA presentes nos documentos, tendo em vista as três macrovertentes anteriormente discutidas: conservacionista, crítica e pragmática.

Ressaltamos, entretanto, que embora a análise tenha tido como recorte os IF, os cursos de Licenciatura em Química ofertados nas universidades também precisam ser analisados em termos de perspectiva de EA, pois são ofertados em maior quantidade e há mais tempo. O que, não necessariamente, garante que os vieses de EA para esses cursos se configurem, em sua maioria, de forma crítica. A discussão sobre as abordagens de EA na formação e professores de Química apresenta ainda lacunas em termos de pesquisa. Nossa afirmação decorre de levantamento na Biblioteca Digital Brasileira de Teses e Dissertações (BDTD) do Instituto Brasileiro de Informação em Ciência e Tecnologia (IBICT), para a pesquisa de mestrado que deu origem a este artigo, pois identificamos que, entre os anos de 2000 e 2020, foram desenvolvidas apenas quinze pesquisas de mestrado e doutorado que têm como enfoque a formação e professores de Química e a EA. ${ }^{39}$

\section{CAMINHOS METODOLÓGICOS DA PESQUISA}

Explicitadas as vertentes teóricas que sintetizam as compreensões de EA que deram suporte à investigação em tela, apresentaremos a seguir os caminhos metodológicos da pesquisa que se configura pela Análise Textual Discursiva (ATD) a partir das propostas pedagógicas de cursos de Licenciatura em Química ofertadas nos Institutos Federais.

Este trabalho se configura como uma pesquisa de caráter qualitativo do tipo análise documental. A análise documental é o tipo de pesquisa que pretende produzir ou reelaborar os conhecimentos descritos em documentos, criando formas de compreender o fenômeno estudado. A análise documental procura centrar seu estudo em documentos que ainda não foram submetidos à processos analíticos, ou seja, busca as fontes primárias da informação desejada. ${ }^{40}$

Como técnica de análise, optou-se pela ATD que se configura como um processo auto-organizado de construção de novos entendimentos que parte de uma reconstrução textual que, assim como a Análise de Conteúdo (AC) e Análise do Discurso (AD), encontrase no domínio da análise textual. No entanto, a caracterização da metodologia como ATD considera, em comparação à $\mathrm{AC}$ e à $\mathrm{AD}$, o caráter hermenêutico evidenciado na Análise textual Discursiva em um processo interpretativo que se anuncia em "movimentos discursivos que constroem e reconstroem as realidades investigadas" (p. 159). ${ }^{41}$ Dessa forma, ao se aprofundar nos documentos, corpus de análise, o pesquisador, em um movimento de produção de novos significados, evidencia o caráter hermenêutico atribuído à ATD no qual processo de criação e imaginação se mostram como necessários para configurar um método analítico em que a autoria interpretativa não é uma opção, mas uma premissa. ${ }^{41}$ Os documentos que envolvem o corpus da pesquisa podem constituir-se de materiais produzidos para análise que se pretende realizar, como no caso de transcrição de entrevistas ou notas de observação, ou de documentos pré-existentes, como documentos oficiais, leis, entre outros.

No caso da presente pesquisa, o corpus de análise foram os Projetos Pedagógicos de Curso (PPC) referentes à cursos de Licenciatura em Química ofertados por institutos federais. Embora existam 96 cursos de Licenciatura em Química oferecidos pelos IF (e-Mec), tivemos acesso a 78 PPC disponibilizados em páginas 
institucionais. No entanto, entendemos que esses documentos representam mais de $80 \%$ da quantidade de cursos ofertados pelos IF, o que nos sinaliza uma análise consistente em termos de compreensão sobre as abordagens ambientais para a formação do professor de química ensejadas nessas propostas. Os PPC analisados são apresentados no Quadro 1S (MS). No processo analítico os documentos foram numerados de 1 a 78 , conforme foram sendo acessados a partir das páginas institucionais dos cursos ou do envio pelas coordenações, quando solicitados por e-mail.

A perspectiva da ATD proposta por Moraes e Galiazzi contempla três etapas: a desmontagem ou fragmentação dos textos, denominada de unitarização; o estabelecimento de relações entre os elementos unitarizados na primeira etapa, etapa compreendida como categorização; e, por último, a captação do novo emergente, que se trata da construção de uma nova compreensão da totalidade do corpus com base nas combinações dos elementos observados e construídos nas etapas anteriores. ${ }^{41}$

A unitarização é a primeira etapa de uma ATD. Constitui-se como processo de desmontagem, ou de desintegração, dos textos componentes do corpus. Pode ser entendida como o focalizar do olhar nos detalhes e nas partes componentes que carregam o sentido do texto. Ocorre através da sua fragmentação e destaque de partes que são consideradas esclarecedoras do todo. Esse é um processo que deve conduzir a uma desorganização do conjunto ordenado dos textos, desordem essa que permite a construção de uma nova ordem, ou seja, uma nova interpretação para o todo.

No processo de unitarização, os textos dos 78 PPC foram lidos e foram destacados trechos que pudessem ter relação com a questão de pesquisa. Esses trechos foram sendo coloridos de forma que as abordagens semelhantes iam sendo coloridas com cores semelhantes. Esses movimentos de unitarização identificou seis unidades de análise: objetivos do curso que envolvem a temática ambiental, perfil esperado do egresso em relação temática ambiental, abordagem da EA no ementário de disciplinas de EA, papel da EA na formação do educador químico, abordagem da questão ambiental nas habilidades e competências a serem desenvolvidas pelo egresso e abordagem da EA no ementário de disciplinas de Química Ambiental.

A partir do entrelace das unidades, iniciou-se o processo de categorização que se dá por meio da comparação entre as unidades de análise, na busca de elementos semelhantes entre elas. O próximo passo é a construção gradativa das categorias, que são formadas por conjuntos de elementos próximos enxergados entre as unidades de análise.

A segunda etapa, a categorização, se dá por meio da comparação entre as unidades de análise, na busca de elementos semelhantes entre elas. Leva, então, à construção gradativa das categorias, que são formadas por conjuntos de elementos próximos enxergados entre as unidades de análise. As categorias são entendidas como partes na organização do novo emergente, uma vez que será a partir delas que se dará a estruturação das novas interpretações do texto original. A criação de categorias pode se estruturar a partir de categorias emergentes, que são evidenciadas ao logo do processo de desvelamento das informações textuais, e as categorias a priori, que são aquelas que já se constituem em elementos questionadores do investigador quando centra-se nos elementos textuais. Esse último formato de categoria foi balizador de nossa análise. A categoria $a$ priori que será discutida no presente texto refere-se às concepções de EA impressas nos PPC.

As unidades de análise objetivos do curso que envolvem a temática ambiental, abordagem da EA no ementário de disciplinas de EA, papel da EA na formação do educador químico e abordagem da EA no ementário de disciplinas de Química Ambiental compõem a categoria discutida neste artigo. As unidades perfil esperado do egresso em relação temática ambiental e abordagem da questão ambiental nas habilidades e competências esperadas para o egresso se entrelaçam na formação de uma segunda categoria analítica que não é abordada no presente artigo. Dessa forma, as discussões da categoria em tela são realizadas a partir dos recortes textuais dos PPC que foram destacados no processo de unitarização.

Após o processo de categorização, a terceira etapa da ATD é captação do novo emergente. Essa terceira etapa se estrutura mediante a descrição e a interpretação das categorias que representam um modo de teorização sobre os fenômenos estudados. Esse é um processo de explicitação de significados e de novas compreensões do texto original que se traduz na produção de um novo texto que, nesse caso, é o artigo em questão.

\section{RESULTADOS E DISCUSSÃO}

No estudo dos 78 PPC que constituem o corpus dessa pesquisa, no que concerne a categoria concepções de EA impressas nos PPC, nos atentamos a duas unidades de análise: objetivos para a formação em EA e conteúdos programáticos nas ementas de disciplinas que discutem EA. A desmontagem dos textos nas referidas unidades nos levou a observar que 37 dos documentos evidenciam uma concepção Conservacionista de EA, enquanto 21 a entendem dentro de uma perspectiva Pragmática e apenas três explicitam uma ótica Crítica. Outros 17 desses documentos não trazem uma abordagem sobre objetivos ou concepções de EA. A seguir, discutiremos os dados da pesquisa à luz dos referenciais teóricos.

\section{A predominância de uma EA de caráter conservacionista}

Os PPC 02, 03, 04, 05, 06, 09, 10, 11, 12, 13, 14, 15, 16, 19, 22, $23,24,25,26,27,29,31,32,33,39,40,45,48,52,55,56,62,70$, 71, 72, 74 e 76, embora abordem a relação do ensino de Química e o respeito ao meio ambiente, ora entrevendo essa discussão em disciplinas de EA, ora diluindo-o entre as disciplinas de cunho específico e pedagógico, expressam esse vínculo dentro de um viés comportamentalista de transformação individual, como se a simples mudança nas atitudes dos sujeitos bastasse para a mitigação do cenário de crise socioambiental que vivenciamos. A discussão da crise ambiental fica reduzida, então, a propagação da lógica de um falso consenso sobre o modo de vida, que impõe a reprodução do modelo social hegemônico vigente como condição básica para a garantia universal de progresso e bem-estar, quando na verdade a supressão da crise ambiental que vivenciamos demanda uma ruptura com esse modelo, contemplando discussões e ações coletivas e não individuais.

Excertos de alguns desses textos são apresentados no Quadro 2, em que evidenciamos o aspecto conservador das propostas de EA expressas nesses PPC por meio das contradições observadas entre os objetivos definidos para a formação docente e os objetivos para a EA. Salientamos que a escolha dos trechos apresentados no Quadro 2 deu-se a partir de recortes representativos que evidenciam construções semelhantes que se repetem nos documentos em termos da abordagem da temática ambiental.

Tecemos aqui uma crítica à perspectiva de formação docente observada nos PPC em que notamos uma compreensão conservacionista de EA, nos quais que se propõe a formação de um profissional crítico, construtivo e socialmente engajado, mas que esvazia o fazer pedagógico do questionamento das condições sociais e do modelo econômico vigente que nos levam à crise socioambiental.

Tais perspectivas não são contraditórias, mas sim complementares, conforme nos reforçam Silva-Sánchez e Guimarães quando 
Quadro 2. Exemplos da contradição entre objetivos de formação docente e objetivos para a EA nos PPC de ênfase conservacionista

\begin{tabular}{|c|c|c|}
\hline PPC & Objetivos para a formação docente & Objetivos para a EA \\
\hline 14 & $\begin{array}{l}\text { Atuar com ética e compromisso com vistas à construção de uma so- } \\
\text { ciedade justa, equânime, igualitária. }\end{array}$ & $\begin{array}{l}{[\ldots] \text { aproximação com o universo prático no que é concernente à }} \\
\text { instrumentação dos alunos para as atividades relacionadas ao meio } \\
\text { ambiente e a ecologia. }\end{array}$ \\
\hline 19 & $\begin{array}{l}\text { Exercício da cidadania, respeitando o direito à vida e ao bem-estar dos } \\
\text { cidadãos. Assumir conscientemente a tarefa educativa cumprindo o } \\
\text { papel social de preparar os(as) alunos(as) para o exercício consciente } \\
\text { da cidadania. }\end{array}$ & $\begin{array}{l}\text { [...] conscientizá-lo para que seja um educador da comunidade na } \\
\text { preservação do meio ambiente ecologicamente saudável. }\end{array}$ \\
\hline 52 & $\begin{array}{l}\text { Propiciar ao estudante uma formação teórico-prática no ensino de } \\
\text { Química, que permita o desenvolvimento de uma visão crítica e uma } \\
\text { intervenção adequada em distintos campos de atividade profissional }\end{array}$ & $\begin{array}{l}\text { Conscientizar o estudante dos problemas mundiais referentes à na- } \\
\text { tureza e estimulá-lo a adquirir um senso de preservação da vida e do } \\
\text { meio ambiente. }\end{array}$ \\
\hline 55 & $\begin{array}{l}\text { Formar profissionais conscientes, competentes, com formação (sólida } \\
\text { base) técnico-científica, comprometidos com a construção de uma } \\
\text { sociedade mais justa. }\end{array}$ & $\begin{array}{l}\text { Formar profissionais abertos ao diálogo, à diversidade e a preservação } \\
\text { do meio-ambiente. }\end{array}$ \\
\hline 71 & $\begin{array}{l}\text { [...] formação de cidadãos conscientes, críticos e com responsabilidade } \\
\text { social, econômica e ambiental. }\end{array}$ & $\begin{array}{l}\text { Compreender o conceito de meio ambiente, no âmbito da preservação } \\
\text { e da sustentabilidade. }\end{array}$ \\
\hline
\end{tabular}

nos lembram que a compreensão do direito a um ambiente saudável define novas regras de reciprocidade e de responsabilidade na relação entre sociedade e meio ambiente, implicando a necessidade de construção de uma nova cidadania definida pela luta e pela prática política. $^{42,43}$

Entretanto, esse enlace é ignorado nesses PPC. Por exemplo, a alusão, no PPC 14, à formação docente para a atuação na construção de uma sociedade justa e igualitária contrasta com os objetivos definidos para a EA, pois nesses, a ação do futuro educador se restringe a "instrumentação dos alunos para as atividades relacionadas ao meio ambiente e a ecologia". Salientamos que esse é o único objetivo apresentado para a EA nesse PPC e, da forma como se explicita, a abordagem visa, de forma específica, apenas a instrumentação que não considera uma discussão mais aprofundada do tema, mas a organização de atividades pedagógicas que têm como foco o meio ambiente e a ecologia. No entanto, há uma crítica à compreensão das questões ambientais no viés da ecologia e, em relação ao meio ambiente, ele precisa ser entendido como campo de relações entre o ser humano e o mundo vivido o que, na perspectiva de instrumentação pedagógica como confecção de materiais didáticos não se efetiva já que tal compreensão demanda uma discussão de caráter filosófico, social e político.

Destaca-se também, nos PPC caracterizados como conservacionistas, a compreensão do desenvolvimento técnico, tecnológico e econômico como via de mão única para um salto na qualidade de vida dos sujeitos. A prática da EA se vê, assim, voltada para a superação dos entraves ao progresso econômico, representados pela ausência de conhecimento dos sujeitos sociais sobre a natureza e à preservação dela. Isso se coaduna à visão conservacionista, definida por Lima, Loureiro e Sauvé, como a concepção de EA que concebe a problemática ambiental de uma perspectiva unicamente ecológica, entendendo o meio ambiente como natureza, o que se afasta do questionamento das razões socioeconômicas e das consequências sociais da crise ambiental..$^{2,24,30}$

Assim, a EA de ênfase conservacionista se propõe a resolver a problemática associada aos danos ambientais conscientizando os seres humanos a mudar seus hábitos na lida com a natureza através do ensino de Ecologia, seguindo a premissa de que a simples mudança de comportamentos individuais seja a solução para uma crise que se constrói no todo. ${ }^{44} \mathrm{O}$ foco na sensibilização do cidadão para um contato íntimo com a natureza, com vistas à atuação desse na preservação e manutenção do meio ambiente saudável, conforme se observa nos PPC 52, 55 e 71, se configura como característica do objetivo instrumentalista da concepção conservacionista de EA.

\section{O Desenvolvimento Sustentável em tela: os PPC de ênfase pragmática}

A desmontagem dos PPC objetos desse estudo, nos leva observar que 21 deles abordam a EA dentro de uma perspectiva pragmática. Os documentos por nós caracterizados como pragmáticos são os PPC 20, 30, 34, 35, 36, 37, 38, 42, 46, 47, 51, 53, 54, 59, 60, 61, 64, 73, 75, 77 e 78. O que se nota nesses documentos é a presença de forte apelo a conceitos como Consumo Sustentável e Desenvolvimento Sustentável. Em consonância com esses pressupostos, os documentos aqui discutidos desenvolvem discussões que, embora no plano aparente, pareçam se dedicar à transformação social, a assimilam na forma de mudanças de cunho comportamentalista, individual e setorial.

A perspectiva pragmática é caracterizada como a concepção de EA que traz como discurso a efetivação de mudanças setoriais na correção de fragilidades dos sistemas de produção e de consumo através da mudança de comportamento dos indivíduos neles inseridos. ${ }^{28,45}$ Sua visão é, portanto, cosmética e de operação de mudanças dentro dos limites permitidos pelo modelo socioeconômico corrente, ausente da pretensão de concretizar o rompimento com ele.

Os PPC 20, 42, 54 e 64, apesar de não possuírem disciplinas dedicadas especificamente à EA, abordam questões inerentes a ela dentro dos objetivos do próprio curso. Eles retratam a intenção da formação de um docente que compreenda as relações entre o desenvolvimento socioeconômico e os impactos ambientais por ele gerados, dentro perspectiva de correção das falhas de um progresso econômico que é tido como intrínseco à melhoria da qualidade de vida.

Os PPC 30, 47, 73 e 75, 77 e 78 também não abrangem componentes curriculares de EA e a abordam em disciplinas pedagógicas e específicas, de cunho obrigatório. No âmbito do PPC 30 essa abordagem é feita nos componentes curriculares Prática Pedagógica IV, Prática Pedagógica V, Prática Pedagógica VII e Prática Pedagógica VIII, em que são tratados temas como consumo sustentável e consumo consciente, que também se coadunam a uma lógica pragmática. No PPC 47, a EA é tratada no componente curricular Educação em Direitos Humanos, Diversidade e Sustentabilidade. Nessa disciplina observa-se a abordagem da relação entre a educação em direitos humanos e a sustentabilidade.

A EA é discutida nas ementas de disciplinas específicas dos PPC 73 e 75 e temas como sustentabilidade e consumo consciente são vinculados aos conteúdos específicos das disciplinas de Química Geral, Química Inorgânica e Físico-química. Na estrutura dos PPC 36, 77 e 78 são dedicados subtópicos para o desenvolvimento da concepção de EA e de seus objetivos. 
Conceitos como justiça socioambiental, cidadania ambiental e a discussão de novas formas de produção e consumo são inseridos dentro de uma lógica comportamentalista e preservacionista de EA, conforme trechos representativos destacados a seguir:

Favorecer uma formação holística que permita ao licenciado compreender a presença e as influências da ciência Química nos diversos âmbitos, com destaque no âmbito tecnológico e ambiental e suas potencialidades para um desenvolvimento socioambiental sustentável. (PPC 51)

Nos componentes curriculares da Tabela 9 a Educação Ambiental será trabalhada a partir da exploração e reflexão de diversos conteúdos e metodologias, como, por exemplo: a relação de tópicos do meio ambiente com a saúde; discussão dos principais avanços tecnológicos com suas implicações e desequilíbrios ambientais; o desenvolvimento do senso crítico quanto ao uso consciente dos reagentes e disposição e descarte correto do material produzido nas aulas e nas indústrias; desenvolvimento do conceito de gestão ambiental e desenvolvimento sustentável. (PPC 78)

Outras características que dão ênfase pragmática à EA no PPC 36 são encontradas na ementa da disciplina específica de Educação Ambiental, voltada para a discussão do Desenvolvimento Sustentável. De acordo com Loureiro, Desenvolvimento Sustentável é um conceito ou um conjunto de princípios que denotam o objetivo de "crescer sem comprometer a capacidade de suporte dos ecossistemas e seus ciclos, garantindo a existência social e de outras espécies em longo prazo" (p. 55). ${ }^{31}$ Esse conceito também é discutido nos PPC $77 \mathrm{e}$ 78, em disciplinas de Química Ambiental. Nesses documentos, o desenvolvimento sustentável é abordado como base para a relação entre o desenvolvimento tecnológico e a busca pelo equilíbrio ambiental.

Embora possuam um componente curricular específico de EA, nos PPC 34 e 51 a formação sob a ótica ambiental também é tratada nos objetivos do curso. O programa curricular da disciplina de EA no PPC 34 nos dá pistas de uma concepção pragmática ao direcionar a discussão dessa para o Desenvolvimento Sustentável, conceito também abordado nos objetivos do PPC 51 que carrega a defesa de sua harmonização com o crescimento econômico. Entendemos que a inserção desse conceito dá a tônica do pragmatismo, uma vez que, a proposta dessa macrotendência se expressa, de forma mais veemente, na substituição da EA por uma Educação para o Desenvolvimento Sustentável. ${ }^{28}$

A sujeição da EA à ênfase pragmática é abordada de maneira ainda mais clara no PPC 59. No corpo do documento a tendência a essa vertente é evidenciada pelo forte apelo à Sustentabilidade como um dos objetivos do curso e por sua proposta de discussão, na ementa da disciplina de EA, das "imposições do desenvolvimento ecologicamente sustentado à Educação Ambiental” (PPC 59).

Também são propostas disciplinas específicas de EA nos PPC 35 e 38. No primeiro, a discussão da formação de novos comportamentos no trato com o meio ambiente, e de políticas de conservação dele, dão o tom sobre a perspectiva de compreensão da EA. No segundo, em um componente curricular denominado Educação Ambiental e Sustentabilidade, a EA é associada ao consumo sustentável e a formas sustentáveis de desenvolvimento econômico. Essas associações podem ser observadas no trecho destacado a seguir:

Proporcionar aos alunos, conhecimentos sobre o diálogo interdisciplinar da Educação Ambiental, com foco nas questões ligadas a sustentabilidade socioambiental, ao exercício da cidadania, bem como na identidade da Educação Ambiental no Mundo, Brasil e em Mato Grosso, e em que medida essa Educação Ambiental pode contribuir com as políticas públicas voltadas para a conservação, como estimulo a reflexão crítica e propositiva da inserção da Educação Ambiental na educação escolar e com a compreensão da Educação Ambiental como integrante do currículo de forma interdisciplinar, bem como, com a Educação Ambiental, construir conhecimentos que ajudem no desenvolvimento de habilidades, atitudes e valores sociais, cuidado com a comunidade de vida, a justiça e a equidade socioambiental, e a proteção do meio ambiente natural $e$ construído. (PPC 35)

Despertar no acadêmico do curso de Licenciatura em Química, valores éticos e de formação da cidadania, que os levem a compreender e usar de modo sustentável os complexos sistemas ambientais dos quais fazemos parte. (PPC 38)

Nos excertos destacados observamos um apelo ao desenvolvimento de novos valores e de novas atitudes no trato com o meio ambiente e no uso dos recursos por ele oferecidos. Essas ideias remetem à lógica de consumo sustentável e de consciência ambiental cidadã, características da EA pragmática que, como apontam Layrargues e Lima, recorrendo ao bom-senso dos cidadãos, os convoca a renunciar parte de seu conforto em prol do que seria um bem maior. ${ }^{28}$

\section{A EA como proposta de embate ao padrão de produção e consumo vigentes}

Apenas três dos PPC analisados apresentam objetivos para a EA que se aproximam da perspectiva crítica. Os PPC 07, 08 e 17 apresentam uma concepção da problemática ambiental em que se pode observar o inter-relacionamento entre questões de ordem social como causa e como fruto dos problemas inerentes ao meio ambiente, dentro de uma proposta de formação de um educador químico consciente da necessidade da mudança de paradigmas na sociedade em que nos encontramos inseridos e, além disso, sensível à incompatibilidade entre a luta pelo direito de condições socioambientais dignas e o modelo socioeconômico vigente.

Tais ideias se relacionam à perspectiva crítica tendo em vista que a entendem como a contraposição às práticas de manutenção do status quo econômico, político e social da EA de ênfase conservacionista. ${ }^{24,30,41}$ Esses autores discutem a perspectiva crítica como a vertente que relaciona a problemática ambiental não unicamente aos conceitos ecológicos, mas sim aos seus múltiplos aspectos causais (políticos, econômicos, sociais, históricos, biológicos).

Os PPC 07 e 08 trazem objetivos muito sintéticos para a EA, o que dificulta uma análise da compreensão dela dentro desses documentos. A ementa e programas das disciplinas que abordam a EA, por outro lado, deixam claro o trabalho e o entendimento da EA enquanto elemento na construção de uma compreensão da crise socioambiental como produto do padrão de produção e consumo predatórios e da necessidade urgente de sua transformação. O Programa Curricular da disciplina de Educação Ambiental do PPC 07 explicita essa perspectiva (Quadro 3):

O PPC 17, por sua vez, dedica uma subseção para a discussão da compreensão de EA na formação de educadores ambientais proposta por esse documento. A EA é aqui defendida como via para a construção de uma nova relação entre sociedade e meio ambiente, que só seria possível através da transição para outro modelo social. 
Quadro 3. Recorte do Programa Curricular da disciplina de EA do PPC 07

Unidade I - Epistemologia da Educação Ambiental

- Uma história social das relações com a natureza.

- A relação sociedade-natureza.

- A Educação Ambiental e os movimentos de transição de paradigmas Unidade II - Histórico das Conferências em Educação Ambiental

- Resgate da Educação Ambiental no Brasil.

Unidade III - Educação Ambiental Transformadora

- As tendências reveladas.

- Educação, emancipação e sustentabilidade: em defesa de uma pedagogia libertadora para a Educação Ambiental.

Unidade IV - Educação no processo de Gestão Ambiental

- Reflexões acerca de nosso olhar sobre as relações entre a sociedade e a natureza.

- Cidadania e justiça ambiental na luta pelo direito de existência.

- Operacionalização das atividades de Educação Ambiental.

Defendemos a Educação Ambiental numa perspectiva crítica, sendo um processo social e cultural que busca construir meios para transformar o nosso modo de existir na natureza, objetivando-se assim a articulação do conhecimento sobre os processos ambientais, a intencionalidade dos sujeitos em sua relação com a natureza e a transformação social, com vistas à substituição radical dos modelos de sociedade que vêm destruindo o planeta. (PPC 17)

O estabelecimento de vínculos entre as relações sociais e a relação homem-natureza que se observa nesses documentos explicita o caráter crítico da EA que se pretende nos cursos por eles orientados. Os conceitos de justiça ambiental, de cidadania ambiental e de transformação social neles presentes são características da EA crítica. Entendemos que esses elementos refletem sua proposta pedagógica que se orienta através da busca pela compreensão, em sua totalidade, do sistema complexo a qual denominamos meio ambiente. Sistema esse que, antes espaço natural, sendo apropriado pelas sociedades humanas fez-se espaço socialmente produzido. ${ }^{43}$

Outra evidência surge nos componentes curriculares de EA dos PPC 07 e 08 é que contemplam a discussão da pedagogia freiriana como fundamentação para o desenvolvimento da sustentabilidade e da emancipação através da EA. A referência à Paulo Freire e à sua pedagogia ressalta a opção pela vertente crítica, dadas suas reflexões sobre a realidade sócio-histórica e a necessidade de sua transformação.

Centrada na problematização das relações homem-mundo, entre elas a relação entre a sociedade e a natureza, a Educação Libertadora visa desvencilhar o processo educativo da visão fragmentada de mundo e a superação da consciência ingênua em busca da consciência crítica. Esse processo de conscientização permite ao homem compreender as condições de opressão a que está sujeito e que essa realidade é mutável. ${ }^{46}$

Os referidos autores apontam o processo de tomada de consciência como a possibilidade de transformação das relações construídas entre a sociedade e o ambiente. Conscientização essa que se dá de forma histórica, mediata e política e que não se limita a apreensão de conceitos e conhecimentos sobre o mundo natural, mas sim que se pauta pela reflexão sobre os caminhos que nos trouxeram ao momento presente e na ação sobre essa realidade na busque de uma ruptura com a cultura e com o modelo societário hegemônicos.

No contexto das IES, as perspectivas ambientais críticas não necessariamente precisam se prender ao recorte de cursos e matrizes curriculares, mas podem alçar outros lugares de inserção vislumbrando a instituição como um todo. Nesse sentido, Sundan e Zuin investigaram um projeto de formação socioambiental, de caráter emancipador, desenvolvido junto a servidores públicos de uma universidade pública de São Paulo. As autoras apontam a importância do desenvolvimento desse projeto que compreende a perspectiva emancipadora como aquela que "potencializa uma resistência à racionalidade instrumental e ao sistema de produção atual, busca politizar os processos formativos e dar um passo na superação do senso comum sobre as questões socioambientais na instituição" (p. 223 , tradução nossa). ${ }^{47}$

\section{A ausência de abordagem de objetivos para a EA: uma questão de preocupação política}

A perspectiva transformadora presente na abordagem freiriana da EA, pautada pela emancipação e a conscientização dos sujeitos históricos de que a relação homem-natureza se dá no plano político do meio ambiente como construto dessa relação nos evidencia a vinculação dos PPC 07, 08 à EA crítica.

Finalizando a apresentação das análises, salientamos que a desmontagem dos PPC 01, 18, 21, 28, 41, 43, 44, 49, 50, 57, 58, 63, 65, 66, 67, 68 e 69 demonstra que, nesses textos, não há abordagem dos objetivos para a formação em EA. Embora esses PPC indiquem uma formação docente voltada para questões de cunho social, essas não se encontram vinculadas à problemática ambiental. Essa omissão é preocupante considerando-se o contexto atual relacionado às questões ambientais, principalmente no Brasil, em um momento que os embates ideológicos são reforçados em defesa de interesses que visam o desmonte e enfraquecimento das políticas ambientais vigentes no país.

Esses documentos se tornam, assim, omissos no tratamento socioambiental na formação docente, de acordo com a perspectiva crítica da EA, na qual embasamos nossa análise. Entendemos que essa negligência se dá no contexto de uma compreensão que aparta os problemas relativos ao meio ambiente da prática social, entre elas o futuro ato docente. Esse olhar nos leva a entender que esses PPC, embora não o evidenciem de forma imediata, carregam em seu bojo uma concepção conservacionista de EA.

\section{CONSIDERAÇÕES FINAIS}

A inserção das questões ambientais nos documentos balizadores da formação de educadores químicos nos IF se dá muito mais dentro de um viés comportamentalista de mudança das ações individuais do futuro profissional, atendendo a um novo perfil de conservacionismo. Essa leitura dos PPC, considerando a especificidade da inserção da EA nesses documentos, reflete uma compreensão da crise ambiental de forma apolítica, cosmética e desvinculada da necessária crítica ao capital e ao sistema social que nele se funda. Isso pode reverberar em uma formação, em termos de EA, destituída de um questionamento crítico aos agravos à natureza, tão caro à formação cidadã integral e politicamente ativa.

Um dos aspectos que pode explicar a evidência das perspectivas de EA conservacionista e pragmática na formação de educadores químicos pode ser o próprio perfil e natureza técnica e tecnológica dos Institutos Federais. Cabe ressaltar que essas IES não possuem tradição na formação de professores, um campo no qual é de suma importância o entrelace de saberes específicos de conteúdo e saberes pedagógicos. A EA se configura nesse entrelace, pois discute questões educacionais, mas precisa dos conhecimentos biológicos, físicos e químicos, dentre outros, para dar sentido às abordagens da temática ambiental. A partir disso, entendemos que nos IF essas relações estão em processo de construção. 
Ressaltamos ainda que, embora a EA se configure como um importante elemento formativo para os professores de Química, considerando-se a problemática ambiental no contexto da crise civilizatória que vivenciamos, um ponto a ser destacado é que, nos documentos balizadores dos cursos analisados, há pouca inserção da EA em disciplinas específicas da Química. Isso evidencia uma separação entre o conhecimento de EA e o conhecimento químico, o que denota uma compartimentalização do saber que, em termos de formação de um profissional da educação química, trará prejuízos tendo em vista que no espaço de atuação do futuro licenciado, a Educação Básica, as abordagens de EA devem perpassar o currículo em um movimento interdisciplinar que lhe é característico.

Tentamos, nesta investigação, colaborar com discussões que possam contribuir com esse contexto formativo que, em decorrência do número de licenciaturas em Química ofertadas pelos IF em todo o país, já se configura como importante locus de formação de educadores químicos dentro do cenário nacional.

\section{MATERIAL SUPLEMENTAR}

Quadro 1S, em que constam os PPC de Licenciaturas em Química dos IF que se constituíram como corpus da pesquisa, disponível em https://quimicanova.sbq.org.br em formato PDF, com acesso livre.

\section{REFERÊNCIAS}

1. Ribeiro, J. A. G.; Cavassan, O.; GÓNDOLA, Enseñanza y Aprendizaje de las Ciencias, 2013, 8, 2, 61.

2. Lima, G. F. C.; Educação Ambiental no Brasil: Formação, Identidade e Desafios. $1^{\text {a }}$ ed., Editora Papirus: Campinas, 2011.

3. Moraes, A. C.; Revista Lutas Sociais 2006, 15, 40.

4. Ferreira, L. C.; Ambiente \& Sociedade 2002, 5, 35.

5. Zuin, V. G.; A Inserção da Dimensão Ambiental na Formação de Professores de Química, $1^{\mathrm{a}}$ ed., Editora Átomo: Campinas, 2011.

6. Flores, P. C. P.; Atz, A. P.; Hupffer, H. M. Em A atualidade das denúncias de Rachel Carson na Obra Primavera Silenciosa em relação ao uso do Glifosato no Brasil; Hupffer, H. M., Engelmann, W., Weyermüller, A. R., eds.; $1^{a}$ ed., Casa Leiria: São Leopoldo, 2019, cap. 1.

7. Layrargues, P. P.; Tese de Doutorado, Universidade Estadual de Campinas, Brasil, 2003.

8. Cassino. K. F. D.; Echeverrìa, A. R.; Quim. Nova Esc. 2013, 36, 220.

9. Queiroz, F. L. L.; Camacho, R. S.; Fórum Ambiental da Alta Paulista 2016, 12,1 .

10. Moradillo, E. F.; Oki, M. M.; Quim. Nova 2004, 27, 332.

11. Brasil; Lei 6.938 de 31 de agosto de 1981, disponível em http://www. planalto.gov.br/ccivil_03/leis/16938compilada.htm, acessada em dezembro 2020

12. Brasil; Lei 9.795 de 27 de abril de 1999, disponível em http://www. planalto.gov.br/ccivil_03/leis/19795.htm, acessada em dezembro 2020.

13. Layrargues, P. P. Em $O$ cinismo da reciclagem: o significado ideológico da reciclagem da lata de alumínio e suas implicações para a educação ambiental, Loureiro, C. F. B., Layrargues, P. P., Castro, R. S., eds.; $1^{a}$ ed.; Cortez: São Paulo, 2002, capítulo 7, p. 179-219.

14. Brasil; Lei 9.795 de 27 de abril de 1999, disponível em http://www. planalto.gov.br/ccivil_03/leis/19795.htm, acessada em dezembro 2020.

15. Brasil; Lei 13.005 de 25 de junho de 2014, disponível em http://www. planalto.gov.br/ccivil_03/_ato2011-2014/2014/lei/113005.htm, acessada em dezembro de 2020.

16. Brasil; Resolução $\mathrm{n}^{\circ} 2$ do Conselho Nacional de Educação de 15 de junho de 2012, disponível em http://portal.mec.gov.br/dmdocuments/ rcp002_12.pdf, acessada em dezembro 2020.

17. Cassiano, K. F. D.; Tese de Doutorado, Universidade Federal de Goiás, Brasil, 2017
18. Quinelato, A. L.; Lindino, T. C. VIII Encontro de Pesquisa em Educação Ambiental, Rio de Janeiro, 2015.

19. Brasil; Resolução $\mathrm{n}^{\circ} 1$ do Conselho Nacional de Educação de 18 de fevereiro de 2002, disponível em http://portal.mec.gov.br/seesp/arquivos/ pdf/res1_2.pdf, acessada em dezembro 2020.

20. Brasil; Resolução ${ }^{\circ} 2$ do Conselho Nacional de Educação de 1 de julho de 2015, disponível em http://portal.mec.gov.br/docman/agosto-2017pdf/70431-res-cne-cp-002-03072015-pdf/file, acessada em dezembro 2020.

21. Brasil; Resolução $n^{\circ} 2$ do Conselho Nacional de Educação de 20 de dezembro de 2019. Disponível em: http://portal.mec.gov.br/docman/ dezembro-2019-pdf/135951-rcp002-19/file, acessada em dezembro 2020.

22. Brasil; Parecer CNE/CES 1.303/2001 aprovado em 06 de novembro de 2001. Disponível em: http://portal.mec.gov.br/sesu/arquivos/ pdf/130301Quimica.pdf, acessado em dezembro 2020.

23. Modesto, M. A.; VIII Encontro de Pesquisa em Educação Ambiental, Rio de Janeiro, 2015.

24. Sauvé, L.; Educação e Pesquisa 2005, 31, 317.

25. Guerra, A. F. S.; Figueiredo, M. L.; Educar em Revista 2014, 3, 109.

26. Mesquita, N. A. S.; Cardoso, T. M. G.; Soares, M. H. F. B.; Quim. Nova 2013, 36, 195.

27. Lima, F. B. G.; Revista Eixo 2013, 2, 83

28. Layrargues, P. P.; Lima, G. F. C.; Ambiente \& Sociedade 2014, 17, 23.

29. Gonçalves, C. W. P.; Os (des)Caminhos do Meio Ambiente, $2^{\mathrm{a}}$ ed., Editora Contexto: São Paulo, 2006.

30. Loureiro, C. F. B. Em Problematizando conceitos: contribuição à práxis em Educação Ambiental; Loureiro, C. F. B., Layrargues, P. P., Castro, R. C., eds.; $1^{\text {a }}$ ed.; Cortez: São Paulo, 2006, capítulo 4.

31. Loureiro, C.F.B.; Sustentabilidade e Educação: um olhar da Ecologia Política, $1^{a}$ ed., Editora Cortez: São Paulo, 2012.

32. Loureiro, C. F. B.; Layrargues, P. P.; Trab. Educ. Saúde 2013, 11, 53.

33. Carvalho, I. C. M.; Anais do Simpósio Sul-Brasileiro de Educação Ambiental, Erechim, Brasil, 2002.

34. Layrargues, P. P.; Pesquisa em Educação Ambiental 2018, 13, 28.

35. Loureiro, C. F. B. Em Educação ambiental crítica: contribuições e desafios; Mello, S. S., Trajber, R., eds.; $1^{a}$ ed., Ministério da Educação / Ministério do Meio Ambiente / UNESCO: Brasília, 2007, cap. 2.

36. Silva, L. M.; Batalha, S. S. A.; Hora, N. N.; Pontes, A. N.; Revista Eletrônica do Mestrado em Educação Ambiental 2013, 30, 290

37. Lenardão, E. J.; Freitag, R. A.; Dabdoub, M. J.; Silveira, C. C.; Quim. Nova 2003, 26, 123.

38. Prado, A. G. S.; Quim. Nova 2003, 26, 738.

39. Magela, W. F.; Dissertação de mestrado, Universidade Federal de Goiás, 2020.

40. Sá-Silva, J.; Almeida, C. D.; Guindani, J. F.; Revista Brasileira de História \& Ciências Sociais 2009, 1, 1 .

41. Moraes, R.; Galiazzi, M. C.; Análise Textual Discursiva, $2^{\mathrm{a}}$ ed., Editora Unijuí: Ijuí, 2011.

42. Silva-Sánchez, S. S.; Plural Revista do Programa de Pós -Graduação em Sociologia da USP 1999, 6, 20.

43. Guimarães, M.; Revista Margens Interdisciplinar 2016, 7, 11.

44. Guimarães, M.; Educação Ambiental Crítica; Layrargues, P. P., ed.; $1^{\text {a }}$ ed., Ministério do Meio Ambiente / Diretoria de Educação Ambiental: Brasília, 2004, cap. 2.

45. Silva, R. L. F.; Campina, N. N.; Pesquisa em Educação Ambiental 2011, $6,29$.

46. Torres, J. R.; Maestrelli, S. R. P.; Revista Eletrônica do Mestrado em Educação Ambiental 2012, 28, 114.

47. Sudan, D. C.; Zuin, V. G.; REMIE - Multidisciplinary Journal of Educational Research 2018, 8, 205. 